\title{
ESTÁGIO ENTRE TETO E PISO: INICIANDO A DOCÊNCIA E A IDENTIDADE PROFISSIONAL
}

\section{ARTIGO ORIGINAL}

NERI, Antônio Avelar Macedo ${ }^{1}$

JÚNIOR, Arnóbio Rodrigues de Sousa ${ }^{2}$

XIMENES, Lucas Teixeira ${ }^{3}$

JÚNIOR, Oscar Soares Araújo ${ }^{4}$

MAIA, Maria das Dores Alexandre ${ }^{5}$

NERI, Antônio Avelar Macedo. Et al. Estágio entre teto e piso: Iniciando a docência e a identidade profissional. Revista Científica Multidisciplinar Núcleo do Conhecimento. Ano 05, Ed. 02, Vol. 03, pp. 55-65. Fevereiro de 2020. ISSN: 24480959, Link de acesso: https://www.nucleodoconhecimento.com.br/educacao/estagioentre-teto-e-piso

\footnotetext{
${ }^{1}$ Mestre em Teologia com Linha de Pesquisa em Ética e Gestão, Especialista em Língua Portuguesa, Graduado em Pedagogia, História e Geografia.

2 Técnico em Edificações, graduando em licenciatura em Geografia e bolsista do Programa Institucional de Bolsa de Iniciação à docência.

${ }^{3}$ Graduando em licenciatura em Geografia e bolsista do Programa Institucional de Bolsa de Iniciação à Docência.

${ }^{4}$ Especialista no ensino de matemática pela Faculdade do Maciço de Baturité (FMB), graduando em licenciatura em Matemática, ex - bolsista do Programa Institucional de Bolsa de Iniciação à docência.

${ }^{5}$ Graduanda em licenciatura em Geografia e bolsista do Programa Institucional de Bolsa de Iniciação à Docência.
} 


\section{RESUMO}

O presente trabalho tem como objeto investigativo o estágio supervisionado entre o teto e o piso: iniciando à docência e buscando alternativas de ensino para a construção da identidade profissional. A partir do eixo temático: iniciação à docência e métodos alternativos de ensino, buscou-se investigar o estágio supervisionado como categoria de análise para a profissionalização docente, tendo como pano de fundo a pesquisa bibliográfica e a etnometodologia (resultante das experiências vivenciadas nos cursos de licenciatura do IFCE- campus Crateús).

Palavras-Chave: Estágio, ensino, métodos, docência, profissionalização.

\section{INTRODUÇÃO}

É através da educação, que os sujeitos agregam os conhecimentos necessários para construção de sua autonomia e, consequentemente possam acessar todo um conjunto de bens e serviços disponibilizados pela sociedade. Trata-se de um direito fundamental, em que todos devem ter acesso a ela de forma igualitária sem qualquer tipo de restrição.

A educação pode acontecer na vida familiar, no trabalho, na convivência humana, bem como nas instituições de ensino e pesquisa. Historicamente, a educação no Brasil sempre foi palco de baixo investimento, atrasos e sucessivas crises. A modernização do sistema, a elaboração de legislação específica, a profissionalização docente e projetos de valorização e prestígio da carreira ainda são temas que não receberam a devida atenção, o que projeta para o futuro próximo um possível apagão da docência.

Essa área tem um reduzido número de neo-docentes interessados em integrar o magistério da educação básica, normalmente optam por outras carreiras, por visualizarem maior prestígio social e valorização salarial.

A formação de professores no Brasil, recentemente teve significativos esforços para superar as lacunas históricas decorrentes dos séculos de atraso educacional, e de políticas públicas que oportunizassem a valorização do magistério. 
Neste interim, destacaremos pontualmente, algumas normatizações que foram determinantes para tentar suprir as necessidades e minimizar alguns problemas, nesta perspectiva destacam-se as seguintes políticas da formação e valorização da profissão docente: A Constituição Federal de 1988, em seu Art. 205, A Lei oㅜ 9.131, de 24 de novembro de 1995, A Lei o 9.394, de 20 de dezembro de 1996, Programas de apoio à formação docente, Programa Institucional de Bolsa de Iniciação à Docência (PIBID), o Plano Nacional de Formação de Professores da Educação Básica (PARFOR), e o Programa de Consolidação das licenciaturas (Pro docência), Plano Nacional de Educação (PNE) 2014-2024: que dedica quatro (15, 16, 17 e 18) das suas 20 metas à valorização dos profissionais do magistério e à primeira formação e à formação continuada de docentes.

Mesmo com as recentes iniciativas de políticas públicas, ainda há uma lacuna gigantesca na formação de professores no Brasil e na valorização do magistério, bem como, uma distância quilométrica entre o teto (curso de formação de professores) e o piso (chão da escola). Nesta perspectiva refletiremos sobre a formação inicial, onde o estágio supervisionado será a categoria de análise do objeto investigado que poeticamente delimitamos em "entre o teto e o piso: iniciando à docência e buscando alternativas de ensino para a construção da identidade profissional”.

O estágio supervisionado é um momento indispensável no processo de desenvolvimento e aprendizagem e na formação do estudante. Uma de suas principais finalidades é fazer com que o aluno mantenha contato direto com a prática docente.

De acordo com Ponte (1998) o desenvolvimento profissional do docente, deve ser ininterrupto e ativo, no qual o professor é protagonista em sua formação e deve assumir a responsabilidade por esse processo, que tem como suporte principal, na formação inicial e na continuada.

Nesse sentido, entende-se que a formação pode e deve beneficiar o crescimento profissional do professor, que acontece em dois âmbitos intrinsicamente ligados, ou seja, o primeiro refere-se ao desenvolvimento do conhecimento e o segundo diz 
respeito à identidade profissional, em que esta último tem sido de fundamental relevância no panorama da formação docente (PONTE; CHAPMAN, 2008).

Para tanto, é preciso desenvolver um ensino dinâmico e estimulante. Dinâmico para motivar os educandos em situações de aprendizagem; estimulante, no sentido de envolver os educandos em situações que privilegiem a prática reflexiva, a qual deve desenvolver práticas de leitura, de interpretação, de escrita e de diálogo. Na área da educação, essa atividade é oferecida nos cursos de licenciatura a partir da metade da graduação e que vai além da proposta curricular.

Além disso, pode proporcionar a oportunidade de perceber se a escolha feita condiz realmente com o tipo de profissão que se deseja seguir posteriormente.

\section{METODOLOGIA}

Para melhor compreender e explicar os impactos dessa metodologia no ensino e aprendizagem na formação de professores e tendo o Estágio como categoria de análise, esta pesquisa qualitativa utilizar-se-á da modalidade da pesquisa bibliográfica e das experiências relatadas pelos acadêmicos dos diferentes cursos de licenciatura do Instituto Federal de Educação, Ciência e Tecnologia do Ceará (IFCE) Campus Crateús.

Conforme Fonseca (2002, p. 31):

[...] qualquer trabalho científico inicia-se com uma pesquisa bibliográfica, que permite ao pesquisador conhecer o que já estudou sobre 0 assunto (...), procurando referências teóricas publicadas com o objetivo de recolher informações ou conhecimentos prévios conhecer sobre o problema a respeito do que se procura a resposta.

Compartilhando o pensamento de Luckesi (1998, p. 89) quando afirma que "toda descoberta nada mais é que um conhecimento provisório da realidade analisada", construímos um processo de escutatória e análise dos relatórios físicos, que muito contribuiu para a realização da etnometodologia, onde as reflexões eram 
compartilhadas e colocadas em categorias para uma melhor compreensão das diferentes realidades vivenciadas no Estágio Supervisionado. Posteriormente, foi utilizado diálogos constantes com diferentes autores que versam sobre a temática investigada.

Acredita-se que o uso dessa metodologia não são verdades absolutas e inquestionáveis, ou melhor, estas não serão páginas de um livro de receita infalível para se obter sucesso, mas sim, uma possibilidade de entender que se deve ensinar e aprender de forma dinâmica, dialogada e contextualizada, estimulando as trocas de experiências que também, se produz conhecimento e saberes coletivos, neste cenário inacabado que é a formação de professores.

Cabe ainda destacar, que não foi realizada uma pesquisa de campo, mas sim, uma análise dos relatórios de estágio supervisionado através das vivências e observações dos relatos, bem como dos experiências socializadas pelos estagiários nas rodas de conversas, com a finalidade de se obter um aprofundamento acerca do tema abordado.

\section{RESULTADOS E DISCUSSÕES}

O vocábulo "docente" é de origem do verbo latino "docere" que significa "ensinar". "Ensinar" é um verbo bitransitivo por aceitar dois complementos, um objeto direto alguma coisa- e um objeto indireto- a alguém. Um momento marcante na formação de qualquer profissional é aquele no qual a teoria e prática têm uma aproximação. $\mathrm{O}$ estágio supervisionado oportuniza essa aproximação, primeiramente em forma de observação e posteriormente em regência. Esse momento de observar e buscar compreender o funcionamento do Ensino e a partir dele buscar métodos que contribuam com a sua evolução tanto no que se refere ao ensino quanto à aprendizagem dos alunos da escola anfitriã.

Há nas atividades propostas de um riquíssimo aprendizado visto que o licenciando sai do seu universo acadêmico e adentra o universo escolar real. Segundo Paulo Freire (1996), ensinar significa criar possibilidades para a produção ou construção do 
conhecimento, e isso não é uma tarefa fácil, pois demanda muita dedicação. Exercer a docência exige do profissional professor a consciência de que "em toda ação docente, encontram-se uma dimensão técnica, uma dimensão política, uma dimensão estética e uma dimensão moral" (RIOS, 2011, p. 93).

Carregando consigo as diversas teorias e diretrizes curriculares estudadas nos semestres que antecedem ao estágio, o graduando ingressa na comunidade escolar e começa a exercitar sua visão de pesquisador sobre tudo que envolve a Escola na qual desenvolverá suas atividades. Desnuda-se da visão de um estudante e veste-se da visão crítico-reflexiva de um profissional em formação que busca entender os processos de ensino e de aprendizagem bem como problematizar as lacunas visando descobrir meios de aperfeiçoar suas concepções de educação e tornar-se um educador preparado para contornar os desafios que surgirão em seu caminho.

O estágio é um período da graduação obrigatório e necessário para a formação docente, pois é a partir do estágio que o estudante tem a oportunidade de ter contato com a sua futura prática profissional. Vale ressaltar que esta aproximação é de suma importância, pois é preciso adapta-se ao meio escolar a fim de que seu papel, enquanto docente seja eficaz. Além disso, o estágio proporciona uma aproximação com professores formados que atuam na área. Como ressalta Libâneo (1994, p. 78) "a interação professor-aluno é um aspecto fundamental da organização da situação didática, tendo em vista alcançar os objetivos do processo de ensino: a transmissão e assimilação dos conhecimentos, hábitos e habilidades".

A escola é um espaço ativo, devido a sua constituição por sujeitos históricos, agentes determinantes na construção de sua realidade a partir dos conflitos que vivenciam, assim como por suas relações sociais, políticas e culturais. Cada aluno traz consigo um conjunto de conhecimentos e saberes prévios oriundos de seu contexto familiar, social e/ou multi-institucional. Também apresentam habilidades e sonhos diferenciados. Partindo desse pressuposto há uma relação quase indissociável entre os dois aspectos mencionados. O estágio visa dar início as vivências docentes do graduando bem como oportunizar uma visão crítico reflexiva dos problemas reais que surgem no cotidiano escolar. 
"É necessário, pois, que as atividades desenvolvidas no decorrer do curso de formação considerem o estágio como um espaço privilegiado de questionamento e investigação" (PIMENTA; LIMA, 2012, p. 112). Isso significa que o estágio também se configura como pesquisa, sendo assim, requer coleta de dados, análise e discussão do que foi observado, vivenciado e concluído. Portanto, são as disciplinas estudadas ao longo do curso que darão subsídios para tal momento de reflexão.

É uma grande oportunidade de refletir e realizar certo comparativo entre as ideias que foram discutidas no âmbito universitário e a forma como os docentes a serem observados desenvolvem seu trabalho. Isso pode, muitas vezes causar um verdadeiro espanto no estagiário em processo de aprendizagem. Selma Garrido Pimenta e Maria Socorro Lucena Lima ponderam sobre tal assunto da seguinte maneira:

A perspectiva técnica no estágio gera um distanciamento da vida e do trabalho concreto que ocorre nas escolas, uma vez que as disciplinas que compõem os cursos de formação não estabelecem os nexos entre os conteúdos (teorias?) que desenvolvem e a realidade nas quais 0 ensino ocorre (PIMENTA; LIMA, 2012, p. 39).

A dicotomia teoria/prática sempre rendeu várias discussões entre especialistas de diversas áreas de atuação. No entanto, todos sabem que é necessário haver uma relação de perfeita harmonia entre esses dois campos. O estágio é muito importante para estabelecer esse vínculo e gerar uma aproximação entre escola e universidade. De acordo com Pimenta e Lima (2012):

[...] o estágio, se caracterizaria mais como uma interação do que como uma simples intervenção, abrindo-se a possibilidade de uma ação entre a universidade e a escola, na qual professores-alunos e professor de estágio também atualizam seus conhecimentos acerca da profissão (PIMENTA; LIMA, 2012, p. 115).

Segundo as mesmas autoras, não se pode reduzir o estágio às noções de prática instrumental e criticismo. A separação entre teoria e prática acarretará em um 
desenvolvimento superficial das atividades na escola, pois, nessa perspectiva, o estágio se trata de teoria e prática e não teoria ou prática. Elas ainda ressaltam que:

[...] a finalidade do estágio é propiciar ao aluno uma aproximação à realidade na qual atuará. Assim o estágio se afasta da compreensão até então corrente, de que seria aparte prática do curso. As autoras defendem uma nova postura, uma redefinição do estágio que deve caminhar para a reflexão a partir da realidade (PIMENTA; GONÇALVES, 1990 apud PIMENTA; LIMA, 2012, p. 45, grifos do autor).

É possível notar que é extremamente importante que o estudante adote uma postura crítica ao fazer suas ponderações sobre o que foi observado, é necessário refletir a respeito das práticas para não haver apenas uma repetição metódica de algo que, muitas vezes, não é o ideal. Pimenta e Lima (2012) dizem que é importante esse modo de aprendizagem por meio da observação, já que nesse processo os alunos podem selecionar aquilo que consideram mais adequado e adaptar aos contextos em que se encontram.

A escola, em particular a sala de aula, é um espaço de vivências e troca de experiências. Assim, é importante que o futuro professor conheça como se desenvolve o ensino e aprendizagem em diferentes componentes curriculares. Para compreender o processo de ensino, é importante que essa pesquisa considere que o ensino sofre a influência de modelos pedagógicos social e historicamente construídos. Segundo Becker (1995), existem três Modelos Pedagógicos: Pedagogia Diretiva, Pedagogia não Diretiva e Pedagogia Relacional.

O primeiro Modelo Pedagógico descrito por este autor (1995) é a chamada Pedagogia Diretiva, aquela frequentemente chamada de tradicional. As principais características desta pedagogia é um ensino centrado no professor, onde aluno deve receber e memorizar as informações (conteúdos) de seu mestre, porque ele é o único detentor de todo o conhecimento. Segundo Becker (1995, p. 15): 
As carteiras estão devidamente enfileiradas suficientemente afastadas uma das outras para que os alunos não troquem conversas. Se o silêncio e a quietude não se fizerem logo, o professor grita para um aluno, xingará outra aluna até que a palavra seja monólogo seu. Quando isso acontece ele começa a dar aula... O professor fala e o aluno escuta. O professor dita e o aluno cópia. $O$ professor decide o que fazer e o aluno executa. O professor ensina e o aluno aprende.

Essas ideias, na perspectiva do mesmo autor, justifica que este tipo de prática pedagógica está diretamente relacionada à epistemologia "empirista", segundo a qual, o indivíduo quando nasce, nada possui em relação ao conhecimento, isto é, trata-se de um caderno em branco, no qual o docente, o considera assim também a cada novo conteúdo situado em sua grade curricular (BECKER,1995).

Neste tipo de pedagogia o professor não está preocupado com os resultados obtidos, sua única preocupação é em cumprir rigorosamente um determinado currículo. Podese assim afirmar que o ensino ocorre verticalmente, professor ensina e aluno aprende. No seu imaginário, segundo Becker (1995, p. 18), o professor acredita que:

[...] ele, e somente ele, pode produzir algum novo conhecimento no aluno. $\mathrm{O}$ aluno aprende se, e somente se, o professor ensina. $\mathrm{O}$ professor acredita no mito da transferência do conhecimento: o que ele sabe, não importa o nível de abstração ou de formalização, pode ser transferido ou transmitido para o aluno.

Enquanto que na Pedagogia Diretiva o professor "vê seu aluno como alguém que nada sabe" (BECKER, 1995, p. 17). Esse modelo pedagógico "o professor como um auxiliar do aluno, um facilitador" (BECKER, 1995, p. 19). O professor que segue esta pedagogia acredita que o aluno aprende por si mesmo e que a aprendizagem é determinada por questões hereditárias. Esta forma de compreender o processo de ensino-aprendizagem tem fundamentação "apriorista", ou seja, na crença de que cada indivíduo já nasce com uma bagagem hereditária, que determina um grau (maior ou menor) na capacidade de aprendizagem. 
O terceiro e último, modelo pedagógico denominado por Becker (1995) é denominado Pedagogia Relacional. Nesta pedagogia o ensinar significa explorar, problematizar e direcionar o então conhecido para o desconhecido, enquanto o aprender significa agir e problematizar sua ação. A aprendizagem é um processo contínuo, mas de certa forma, criativo, pois significa criar novos conhecimentos, construindo "novas respostas para antigas perguntas", ou seja, aprender não é apenas repetir o passado (repetir métodos de resolução, em particular na formação de professores), mas sim, desenvolver a capacidade de reconstruir.

Em outras palavras, o professor [grifo nosso] sabe que há duas condições necessárias para que algum conhecimento novo seja construído: a) que o aluno aja (assimilação) sobre o material que o professor presume que tenha algo de cognitivamente interessante, ou melhor, significativo para o aluno; b) que o aluno responda para si mesmo às perturbações (acomodação) provocadas pela assimilação do material, ou, que o aluno se aproprie, em um segundo momento, não mais do material; tal processo far-se-á por reflexionamento e reflexão (Piaget, 1977), a partir das questões levantadas pelos próprios alunos e das levantadas pelo professor e de todos os desdobramentos que daí ocorrerem (BECKER, 1995, p. 24).

Tais referências estimulam pesquisar novas metodologias de ensino, na perspectiva de que estimulem a prática do diálogo, da reflexão e da escrita, certamente contribuirão para a superação do ensino tradicional. A aprendizagem é um processo contínuo na vida do ser humano, o que quer dizer que se aprende em toda e qualquer situação do dia a dia. Interagindo com o meio o qual está inserido essas novas aprendizagens vão potencializando, transformando comportamentos e desenvolvendo habilidades.

Segundo La Rosa (1993, p. 29), "tudo o que o homem aprende não é estático ou inevitável, mas sim caracteriza-se por uma dinamicidade permanente, porque o homem aprende sempre, ou seja, uma aprendizagem leva a outra, como um movimento mais ou menos constante". Para o autor a aprendizagem acontece por 
meio das vivências, experiências e na medida em que são apresentados estímulos diversificados, os quais geram novos comportamentos e possibilidades positivas na formação docente.

\section{CONSIDERAÇÕES FINAIS}

Observa-se que as conhecimentos apreendidos por meio da observação e do exame da conjuntura escolar, especialmente em sala de aula, contribuiu expressivamente para o processo de formação do estagiário, além disso, colabora para a edificação da identidade profissional como futuro educador, apontando desse modo, novas perspectivas na dicotomia ensino e aprendizagem da profissão em docência. Dessa forma, acredita-se que, por meio de uma reflexão sobre a sua prática pedagógica, o professor poderá aprimorar a execução de seu papel.

Vale ressaltar ainda que, é de suma importância que os professores busquem uma formação continuada, tendo em vista a atualização de conteúdos, conhecimentos para que possa ampliar sua prática profissional.

Renovou-se também a crença numa pedagogia transformadora de realidades, capaz de impactar positivamente os estudantes e criar neles um senso crítico reflexivo, entregando assim à sociedade cidadãos mais capacitados para agirem em benefício da melhoria da realidade social por meio de decisões conscienciosas e positivas.

Portanto, pode-se concluir deste objeto investigado, que o estágio é de suma importância tanto para a formação acadêmica, quanto para a vida profissional na docência, pois consegue fazer com que o estudante de licenciatura, faça esta relação e reflexão entre as correntes teóricas vista na universidade e as práticas pedagógicas em sala de aula, corroborando com a profissionalização docente.

\section{REFERÊNCIAS}

BECKER, Fernando. Educação e Construção do Conhecimento. Porto Alegre: Artmed, 1995. p. 15-32. 
FONSECA, João José Saraiva da. Metodologia da pesquisa científica. Fortaleza: UECE, 2002.

FREIRE, Paulo. Pedagogia da autonomia: saberes necessários à prática educativa. 44. ed. Rio de Janeiro: Paz e Terra, 1996.

LA ROSA, Jorge. Psicologia e Educação: o significado do aprender. 7. ed. Porto Alegre: EDIPUCRS, 1993.

LIBÂNEO, José Carlos. Didática. São Paulo: Cortez, 1994.

LUCKESI, Cipriano Carlos et al. Fazer universidade: uma proposta metodológica. 10. ed. São Paulo: Cortez, 1998.

PIMENTA, Selma Garrido; LIMA, Maria Socorro Lucena. Estágio e Docência. 7 ed. São Paulo: Cortez, 2012.

PONTE, J. P. Da formação ao desenvolvimento profissional. In: PONTE, J. P. Actas do ProfMat, Lisboa: APM, 1998, p. 27-44.

PONTE, J. P.; CHAPMAN, O. Preservice mathematics teachers' knowledge and development. In: ENGLISH, L. D. (Ed.). Handbook of international research in mathematics education. 2. ed. New York: Routledge, 2008. p. 225-263.

RIOS, Terezinha Azeredo. Ética e competência. 20 ed. São Paulo: Cortez, 2011.

Enviado: Janeiro, 2020.

Aprovado: Fevereiro, 2020. 